\title{
An Analysis on Wind Speed Forecasting Result with the Elman Recurrent Neural Network Method
}

\author{
Martaleli Bettiza ${ }^{1 *}$, Nola Ritha ${ }^{2}$, Nanang Gusti Rama ${ }^{3}$ \\ ${ }^{1}$ Department of Informatics, Maritime University of Raja Ali Haji, Tanjungpinang, Indonesia
}

\begin{abstract}
Weather factors in the archipelago have an important role in sea transportation. Weather factors, especially wind speed and wave height, become the determinants of sailing permits besides transportation's availability, routes, and fuel. Wind speed is also a potential source of renewable energy in the archipelago. Accurate wind speed forecasting is very useful for marine transportation and development of wind power technology. One of the methods in the artificial neural network field, Elman Recurrent Neural Network (ERNN), is used in this study to forecast wind speed. Wind speed data in 2019 from measurements at the Badan Meteorologi Klimatologi dan Geofisika (BMKG) at Hang Nadim Batam station were used in the training and testing process. The forecasting results showed an accuracy rate of $88.28 \%$ on training data and $71.38 \%$ on testing data. The wide data range with the randomness and uncertainty of wind speed is the cause of low accuracy. The data set is divided into the training set and the testing set in several ratio schemas. The division of this data set considered to have contributed to the MAPE value. The observation data and data division carried out in different seasons, with varying types of wind cycles. Therefore, the forecasting results obtained in the training process are $17 \%$ better than the testing data.
\end{abstract}

\footnotetext{
*Corresponding author: mbettiza@umrah.ac.id
} 


\section{Introduction}

Indonesia is a maritime country in Southeast Asia located between two continents, Asia and Australia, and two oceans, Pacific Ocean and Indian Ocean. Indonesia's land area is $1,922,570 \mathrm{~km}^{2}$, and its water area is $3,257,483 \mathrm{~km}^{2}$. In addition, Indonesia is an archipelagic country with the largest number of islands in the world. Based on data from the Central Statistics Agency (BPS) published in 2017, Indonesia has 17,504 islands spread across 34 provinces [1]. Indonesia's ocean area is much wider than its land area, make it further strengthens Indonesia's position as the largest archipelagic country in the world.

Riau Islands Province (Kepri) is an area with a sea area of $96 \%$ of its total area, $241,215 \mathrm{~km} 2$. Riau Islands Province has the largest number of islands with a total of 2,408 islands [1]. In archipelagic areas, solving transportation problems is a solution for improving logistics distribution networks and shipping marine products from certain regions. Sea transportation is not only influenced by the availability of means of transportation, routes, and fuel requirements, but also influenced by weather factors, such as wind speed and wave height.

The energy sources widely used today, oil and coal, derived from fossils, which are shrinking in number. There have been many studies on other energy sources, classified as new and renewable energy, such as the use of water, solar radiation, wind, and ocean energy. Riau Islands is an area that is rich in potential renewable energy. In archipelagic country, studying the possibility of renewable energy, such as wind speed, becomes very important. The study of wind speed will support further analyses on transportation issues and studies of new and renewable energy potentials.

Several algorithms have been applied on artificial neural networks to forecast wind speed and produce training models with certain accuracy. In this study, the Elman Recurrent Neural Network (ERNN) method used to forecast wind speed.

Zhang [6] has developed an adaptive hybrid model for short-term wind speed forecasting as a result before the accuracy of the single model needs to improve. An adaptive hybrid model based on Variation Mode Decomposition (VMD), Fruit Fly Optimization Algorithm (FOA), Autoregressive Integrated Moving Average Model (ARIMA) and Deep Belief Network (DBN) is proposed [6]. This adaptive hybrid makes the accuracy of the proposed model better than the other models. Xiao [7] also proposed a combined model to improve accuracy in short-term wind speed prediction based on ARIMA-GARCH and Elman method, and these models significantly improved the accuracy. Zhang [8] also performed a study in short-time wind speed prediction using a combined model to obtain better accuracy.

\subsection{Methodology}

\subsubsection{Data}

This study aims to predict short-term wind speed using data over a certain period of observations from the Hang Nadim BMKG station, Batam. Data is recorded every 3 (three) hours for 365 days, in 2019 and not all informatio is filled in or complete. To meet data processing rules, data imputation carried out using the mean, median, and mode values of the original data. A comprehensive data is needed in the prediction process to ensure the accuracy of the results.

Table 1. Wind Speed Data Preparation

\begin{tabular}{|c|c|c|c|}
\hline Date & UTC & $\begin{array}{l}\text { Wind } \\
\text { Speed } \\
(\mathbf{K m} / \mathbf{h})\end{array}$ & $\begin{array}{l}\text { Wind } \\
\text { Speed } \\
(\mathbf{K m} / \mathbf{h})\end{array}$ \\
\hline 01/01/2019 & $00 \mathrm{Z}$ & 5.6 & 5.6 \\
\hline 01/01/2019 & $03 Z$ & 14.8 & 14.8 \\
\hline $01 / 01 / 2019$ & $06 \mathrm{Z}$ & & 12.05 \\
\hline $01 / 01 / 2019$ & $09 \mathrm{Z}$ & 9.3 & 9.3 \\
\hline 01/01/2019 & $12 Z$ & & 9.3 \\
\hline 01/01/2019 & $15 \mathrm{Z}$ & & 9.3 \\
\hline 01/01/2019 & $18 \mathrm{Z}$ & 9.3 & 9.3 \\
\hline $01 / 01 / 2019$ & $21 Z$ & 5.6 & 5.6 \\
\hline 02/01/2019 & $00 \mathrm{Z}$ & & 18.6 \\
\hline 02/01/2019 & $03 \mathrm{Z}$ & 13.0 & 13 \\
\hline 02/01/2019 & $06 \mathrm{Z}$ & 14.8 & 14.8 \\
\hline 02/01/2019 & $09 \mathrm{Z}$ & 14.8 & 14.8 \\
\hline 02/01/2019 & $12 Z$ & 5.6 & 5.6 \\
\hline $02 / 01 / 2019$ & $15 \mathrm{Z}$ & 9.3 & 9.3 \\
\hline
\end{tabular}

The application was built by applying the Elman Recurrent Neural Network algorithm for wind speed forecasting. This process used 2916 wind speed data in 2019. The reliability of the model carried out with variations in the distribution of the dataset. The dataset divided to the training set and testing set to the following scheme: $60 \%$ : $40 \%, 70 \%: 30 \%$, and $80 \%$ : $20 \%$. The learning rate parameter tested varies in value from 0.1 to 0.9 , with an error tolerance of 0.001 and iterations of 50 and 100 .

\subsubsection{MAPE}

The robustness of forecasting results of the three models used in this study will be evaluated using MAPE value as an error indicator.

$$
M A P E=\frac{1}{n} \sum_{t=1}^{n} \frac{y_{t}-f_{t}}{y_{t}} * 100 \%
$$

Intuitively, MAPE represents a mean absolute error between the prediction results and the actual data. Therefore, it is easier to evaluate the result and calculate the accuracy. 


\section{Elman Recurrent Neural Network}

Elman Recurrent Neural Network (ERNN) first developed by Jeff Elman in 1990. ERNN has advantages in predicting time series data. The output from the hidden layer in ERNN performs a feedback process to itself through the recurrent layer, which is known as the context layer. This process strengthens the network to learn, recognize and generate trained data patterns. ERNN consists of four layers: input layer, hidden layer, context layer, and output layer. The figure below shows ERNN network architecture.

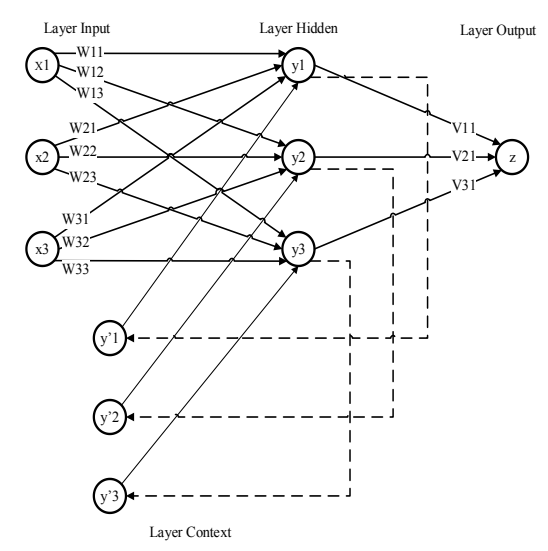

Figure 1. ERNN network architecture

\section{ERNN algorithm steps:}

1. Initialize the weights between the input and hidden layers and the weights between the hidden output layers randomly. Specifies the values for the maximum epoch, learning rate and error tolerance.

2. The input data is sent to all hidden layer units, by multiplying the input value by the weight, and combined with the weight in the context layer, adding up the bias.

net $_{j}(t)=\left(\sum_{i}^{n} x_{i}(t) v_{j i}+\sum_{h}^{m} y_{h}(t-1) u_{j h}\right)+\theta_{j}$

$y_{j}(t)=f\left(\right.$ net $_{j}(t)$

3. The activation function used in the output layer is a binary sigmoid function

$f\left(\right.$ net $\left._{j}\right)=\frac{1}{1+e^{- \text {net }_{j}}}$

4. The output of the hidden layer is multiplied by the weight and added by the bias. The network output calculated using the activation function.

$\operatorname{net}_{k}(t)=\left(\sum_{j}^{m} y_{j}(t) w_{k j}\right)+\theta_{k}$

$y_{k}(t)=g\left(\operatorname{net}_{k}(t)\right)$

\section{Results}

The following is the output of the data training process using the ERNN algorithm.

Using scheme dataset division, $60 \%, 70 \%$, and $80 \%$ training data; error tolerance: 0.001 .

Table 2. Output for $60 \%$ training data

\begin{tabular}{lll}
\hline $\begin{array}{l}\text { Learning } \\
\text { Rate }\end{array}$ & $\begin{array}{l}\text { Epoch }=50 \\
\text { MAPE } \%\end{array}$ & $\begin{array}{l}\text { Epoch }=100 \\
\text { MAPE } \%\end{array}$ \\
\hline 0.1 & 13.988 & 14.058 \\
\hline 0.2 & 13.71 & 13.774 \\
\hline 0.3 & 13.824 & 13.29 \\
\hline 0.4 & 13.581 & 12.585 \\
\hline 0.5 & 13.612 & 13.36 \\
\hline 0.6 & 13.356 & 11.797 \\
\hline 0.7 & 12.614 & 13.412 \\
\hline 0.8 & 13.171 & 14.058 \\
\hline 0.9 & 13.119 & 11.755 \\
\hline
\end{tabular}

Table 3. Output for $70 \%$ training data

\begin{tabular}{lll}
\hline $\begin{array}{l}\text { Learning } \\
\text { Rate }\end{array}$ & $\begin{array}{l}\text { Epoch }=50 \\
\text { MAPE \% }\end{array}$ & $\begin{array}{l}\text { Epoch }=100 \\
\text { MAPE \% }\end{array}$ \\
\hline 0.1 & 14.005 & 14.014 \\
\hline 0.2 & 13.801 & 12.998 \\
\hline 0.3 & 13.755 & 12.653 \\
\hline 0.4 & 13.481 & 12.513 \\
\hline 0.5 & 13.554 & 12.438 \\
\hline 0.6 & 13.208 & 12.464 \\
\hline 0.7 & 13.214 & 12.459 \\
\hline 0.8 & 12.582 & 12.414 \\
\hline 0.9 & 12.804 & 12.385 \\
\hline
\end{tabular}

Table 4. Output for $80 \%$ training data

\begin{tabular}{lll}
\hline $\begin{array}{l}\text { Learning } \\
\text { Rate }\end{array}$ & $\begin{array}{l}\text { Epoch }=50 \\
\text { MAPE } \%\end{array}$ & $\begin{array}{l}\text { Epoch }=100 \\
\text { MAPE \% }\end{array}$ \\
\hline 0.1 & 13.982 & 14.015 \\
\hline 0.2 & 13.205 & 13.551 \\
\hline 0.3 & 13.384 & 12.831 \\
\hline 0.4 & 12.875 & 12.853 \\
\hline 0.5 & 12.807 & 12.824 \\
\hline 50 & 12.872 & 12.845 \\
\hline 76 & 12.805 & 12.807 \\
\hline 42 & 12.22 & 12.823 \\
\hline 23 & 12.814 & 12.81 \\
\hline
\end{tabular}

The results of the system training process were carried using variations of training data $60 \%, 70 \%$, and $80 \%$. Experiment with learning rate 0.1 to 0.8 , error tolerance 0.001 , and epochs 50 and 100, obtained the best training results with the smallest MAPE error value of $11.751 \%$ and the highest accuracy of $88.249 \%$ on $60 \%$ training data experiment with learning rate 0.8 , 
error tolerance 0.001 and the process stops at 94th iteration. Parameters obtained from system training with the smallest MAPE value or highest accuracy used to predict wind speed.

The following is the output of the data testing process using the ERNN algorithm.

Table 5. Output for $40 \%$ testing data

\begin{tabular}{lll}
\hline $\begin{array}{l}\text { Learning } \\
\text { Rate }\end{array}$ & $\begin{array}{l}\text { Epoch }=50 \\
\text { MAPE \% }\end{array}$ & $\begin{array}{l}\text { Epoch }=100 \\
\text { MAPE \% }\end{array}$ \\
\hline 0.1 & 39.115 & 39.433 \\
\hline 0.2 & 38.67 & 38.781 \\
\hline 0.3 & 38.981 & 37.029 \\
\hline 0.4 & 36.802 & 32.87 \\
\hline 0.5 & 38.741 & 35.948 \\
\hline 0.6 & 37.11 & 28.355 \\
\hline 0.7 & 32.243 & 37.539 \\
\hline 0.8 & 36.02 & 28.622 \\
\hline 0.9 & 34.807 & 29.48 \\
\hline
\end{tabular}

Table 6. Output for $30 \%$ testing data

\begin{tabular}{lll}
\hline $\begin{array}{l}\text { Learning } \\
\text { Rate }\end{array}$ & $\begin{array}{l}\text { Epoch }=50 \\
\text { MAPE \% }\end{array}$ & $\begin{array}{l}\text { Epoch }=100 \\
\text { MAPE \% }\end{array}$ \\
\hline 0.1 & 38.86 & 39.188 \\
\hline 0.2 & 39.681 & 34.467 \\
\hline 0.3 & 38.905 & 32.583 \\
\hline 0.4 & 36.842 & 32.029 \\
\hline 0.5 & 37.7 & 29.743 \\
\hline 0.6 & 36.111 & 31.421 \\
\hline 0.7 & 36.02 & 32.387 \\
\hline 0.8 & 33.502 & 31.921 \\
\hline 0.9 & 35.7 & 32.311 \\
\hline
\end{tabular}

Table 7. Output for $20 \%$ testing data

\begin{tabular}{lll}
\hline $\begin{array}{l}\text { Learning } \\
\text { Rate }\end{array}$ & $\begin{array}{l}\text { Epoch }=50 \\
\text { MAPE \% }\end{array}$ & $\begin{array}{l}\text { Epoch }=100 \\
\text { MAPE \% }\end{array}$ \\
\hline 0.1 & 43.741 & 43.938 \\
\hline 0.2 & 41.512 & 43.358 \\
\hline 0.3 & 44.542 & 40.574 \\
\hline 0.4 & 40.502 & 41.376 \\
\hline 0.5 & 41.21 & 40.869 \\
\hline 0.6 & 43.02 & 42.555 \\
\hline 0.7 & 41.184 & 41.722 \\
\hline 0.8 & 43.417 & 43.814 \\
\hline 0.9 & 41.525 & 43.426 \\
\hline
\end{tabular}

\section{Conclusions}

The best accuracy result of $71.38 \%$ is considerednotgood enough for this prediction process. The distribution of data in a fairly far range is analyzed to be the cause. Wind speed in archipelagic areas, such as data collection areas, varies greatly depending on the season. So the use of a fairly long period, one year of data, in this case, affects the results obtained. The distribution of data in the training process and the test process considered to have contributed to the magnitude of the MAPE score. The observation data and data division carried out in different seasons, with varying types of wind cycles, so that the parameters obtained in the training process provide an accuracy difference of up to approximately $17 \%$ in the test process. The results will be better if the data can be first clustered according to the season. The training and testing process carried out on the data in the same season. The number of input variables used considered affecting the results. This research uses time series data with 3 (three) input variables in the prediction process

\section{References}

1. Indonesian Statistic Bureau (BPS), Official Statistical News, Jakarta : Badan Pusat Statistik, 2018.

2. Department of Economic and Social Affairs, Population and Vital Statistics Report, New York : United Nations, 2020.

3. J. Zhang, Y. Wei, Z. Tan, "An Adaptive Hybrid Model for Short-term Wind Speed Forecasting", Elsevier Publisher, 2019.

4. H. Xiao, H. Tang, J. Zhou, "Short-term Wind Speed Combined Prediction Model Based on ARIMA-GARCH and Elman", 2020 Asia Pacific Conference on Image Processing, Electronics, and Computers, 2020

5. H. Liu, Xi-wei Mi, Yan-fei Li, "Wind speed forecasting method based on deep learning strategy using empirical wavelet transform, long short term memory neural network and Elman neural network", Elsevier Publisher, 2018

6. J. Wang, et all.," Forecasting wind speed using empirical mode decomposition and Elman neural network", Applied Coft Computing, Elsevier Publisher, 2014

7. Y. Zhang, C. Zhang, Y. Zhao, S. Gao, "Wind speed Prediction with RBF neural network based on PCA and ICA", Journal of Electrical Engineering, Vol 69 (2018), No 2, 148-155.

8. J. L. Elman, "Finding Structure in Time", Cognitive Science 14, 179-211, 1990.

9. J. Wang, Jun Wang, Wen Fang, and Hongli Niu, "Financial Time Series Prediction Using Elman Recurrent Random Neural Networks", Computational Intelligence and Neuroscience, 2016. 